\title{
Risk Factors, Subtypes and Outcome of Ischaemic Stroke in Kuwait - A Hospital-Based Study
}

\author{
S. Al-Shammria,b,c Z. Shahid ${ }^{b}$ A. Ghalib M.M. Mehndiratta ${ }^{a}$ \\ T.R. Swaminathan ${ }^{c}$ G. Chadha ${ }^{c}$ P.N. Sharmad A.O. Akanji ${ }^{\mathrm{e}}$ \\ aDepartment of Medicine, Faculty of Medicine, Kuwait University, ${ }^{\mathrm{b} K u w a i t}$ Oil Company Hospital, \\ cMubarak Al-Kabir Hospital, Ministry of Health, dHealth Sciences Computer Centre and eDepartment of Pathology, \\ Faculty of Medicine, Kuwait University, Safat, Kuwait
}

\section{Key Words}

Stroke · Stroke subtypes · Risk factors - Atherosclerosis · Kuwait

\begin{abstract}
Objective: To report on stroke subtypes, associated risk factors and outcome in Kuwait. Methods: The records of 62 patients ( 30 male, 32 female) admitted with diagnosis of stroke to Kuwait Oil Company Hospital, Kuwait, a tertiary care hospital, during a 5-year period (1995-1999), were retrospectively reviewed. Results: Small artery infarction was the most common subtype and occurred in 37 subjects $(59.7 \%)$; less common were atherosclerotic large artery strokes (19 patients, 30.6\%) and strokes of cardio-embolic origin ( 6 patients, $9.7 \%$ ). Identifiable risk factors or associated morbidities were hypertension $(72.5 \%)$, diabetes mellitus $(69.4 \%)$, ischaemic heart disease $(14.5 \%)$, history of migraine $(8.1 \%)$, lone atrial fibrillation $(5.0 \%)$, and valvular heart disease $(1.6 \%)$. The most important determinants of a deleterious 30-day outcome, as indicated by severe disability or death, were female gender, lack of use of anti-platelet drugs, presence of a large artery infarction stroke subtype, and cardio-embolic stroke. Conclusion: Prevalence of hypertension and diabetes is high among patients with stroke in
\end{abstract}

\section{KARGER}

Fax +41613061234

E-Mail karger@karger.ch

www. karger.com

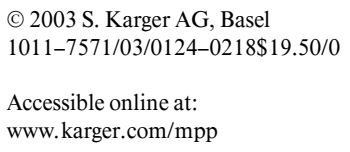

Kuwait, with rates higher than those found in any previous reports from the Gulf region. Two unusual observations were that women had a rather high frequency of stroke, and infarction of the small artery was more common than that of the large artery. Outcome, as indicated by severe disability or death, was worse among women, elderly patients, and those with large artery atherosclerotic and cardio-embolic strokes. There is some evidence that such a deleterious outcome might be ameliorated with use of anti-platelet drugs.

Copyright ( 2003 S. Karger AG, Base

\section{Introduction}

Stroke is an important cause of hospital admissions and long-term disability in most countries. It ranks as the third leading cause of death in developed countries after ischaemic heart disease and cancer [1]. However, in recent times, the incidence of stroke and subsequent mortality appear to have decreased in industrialised countries, probably due to better control of the associated risk factors and improved acute care resources [2]. Most studies indicate that arterial hypertension is the major risk factor for stroke, irrespective of gender and race; other important recognised risk factors are diabetes mellitus,

Dr. Suhail Al-Shammri

Department of Medicine

Faculty of Medicine, Kuwait University

PO Box 24923, Safat 13110 (Kuwait)

Tel. +965 531 9596, Fax +965 533 8907, E-Mail suhail@hsc.kuniv.edu.kw 
cardiac disorders and cigarette smoking [3-5]. It has indeed been suggested that the prevalence of these risk factors appears to be on the increase in most developing countries, which is likely to have implications on stroke prevalence.

The frequency of occurrence of stroke subtypes and their risk factors vary among different countries, including those in the Arabian Gulf region [6-13]. Only limited information is available about the types of stroke and their risk factors in the Gulf region in general, and in Kuwait in particular [11]. There are even fewer articles on its short- and long-term outcomes. A study of this type in Kuwait is important in the light of the extensive modernisation of Kuwaiti society, which began about 3 decades ago and has involved the adoption of Western dietary habits, especially the frequent consumption of 'fast food', and a documented increase in the prevalence of obesity [14].

This study therefore presents preliminary data on the subtypes, risk factors and outcome in 62 patients diagnosed with stroke and seen over a 5-year period (19951999) at the Kuwait Oil Company (KOC) Hospital in Kuwait.

\section{Subjects and Methods}

The case records of 62 patients diagnosed with ischaemic stroke between January 1995 and December 1999 were analyzed retrospectively. These patients had been admitted to the KOC Hospital, a tertiary facility located in the Governorate of Ahmadi, Kuwait, that provides medical services to employees working in the Kuwait oil industry and their family members (total patient base of approximately 70,000). Most of the patients at the hospital are middle class and generally reflect the demographic characteristics of Kuwait. The patients satisfied the World Health Organization criteria of stroke, namely 'a focal or global disturbance of brain function leading to death or persisting for more than 24 hours with no apparent cause other than vascular' [15].

The patients were aged $64.1 \pm 13.2$ years (range $15-85$ years) and included 51 Kuwaitis aged $65.5 \pm 13.6$ years, who were older than the 11 expatriates aged $57.5 \pm 9.2$ years $(\mathrm{p}<0.009)$. There were almost as many men as women (30/32), with no significant difference in their mean ages.

The following information was obtained from the patient case records: age, sex, nationality, past or current history of stroke, transient ischaemic attacks, hypertension, diabetes mellitus, cardiac disease, atrial fibrillation, migraine, cigarette smoking, dyslipidaemia, alcohol and drug intake, especially use of contraceptive pills. A family history of stroke was also elicited. Patients with only transient ischaemic attacks or traumatic brain haemorrhage were excluded.

Hypertension was considered present in patients with an established history of blood pressure (BP) greater than $160 / 190 \mathrm{~mm} \mathrm{Hg}$ or supervised use of antihypertensive medication [16]. The patients who experienced a transient rise of $\mathrm{BP}$ on admission were not consid- ered to be hypertensive. Diabetes mellitus was diagnosed by a past history of supervised diabetes control or persistently high fasting plasma glucose levels ( $>7.0 \mathrm{mmol} / \mathrm{l}$ ) [17]. Dyslipidaemia was considered to be present with supervised hypolipidaemic medication or persistent elevation of fasting plasma total cholesterol $(>5.2 \mathrm{mmol} / \mathrm{l})$ and/or triglyceride levels $(>2.0 \mathrm{mmol} / \mathrm{l})$ [18].

A detailed neurological examination was performed on each patient, as was a detailed physical examination for clinical evidence of cardiac disease, especially ischaemic heart disease, valvular heart disease, tachy- and bradyarrythmia, congenital heart disease and cardiomyopathy. Patients clinically suspected of associated cardiac disease were further evaluated by echocardiography and Holter monitoring. Brain computed tomography (CT) was performed on admission and, if normal, repeated on the 3rd to 7th days to confirm the diagnosis, site and type of stroke in all of the subjects. Stroke subtypes were determined by the following internationally acceptable criteria [19-21]: (a) a cerebral infarct was defined as a hypodense lesion on brain $\mathrm{CT}$, corresponding to the territory of the involved cerebral vessel [20]; (b) a small vessel infarct was defined as a constellation of clinical symptoms and signs showing high correlation with small, deep, rounded infarct due to a single penetrating small arterial occlusion as confirmed by CT [21].

The patients were managed according to standard criteria and procedures [22]. Sixteen of the patients were on anti-platelet therapy (14 on aspirin alone and 2 on aspirin and dipyridamole). Additionally, 3 of the patients received warfarin treatment. None had carotid endarterectomy.

Outcomes were evaluated for each subject 30 days after admission, and the number of deaths and degrees of residual disability (nil, slight, moderate and severe) were assessed for each subject by internationally verifiable criteria [22].

\section{Statistical Analysis}

Data management and statistical analysis were carried out using SPSS (PC version 11.0). Means were compared using Mann-Whitney U-test, other comparisons for outcomes and relationships with specific risk factors or co-morbidities were assessed by applying $\chi^{2}$ or Fisher's test. A probability level of $p<0.05$ was considered significant.

\section{Results}

Apart from the age difference, clinical presentation, management and outcome of ischaemic stroke did not differ significantly between Kuwaitis and non-Kuwaitis, and in view of the relatively small subject numbers, both groups were merged for subsequent analyses and discussion.

The prevalence of risk factors for stroke is shown in table 1 . In this stroke population, the prevalence of hypertension was $72.5 \%$, diabetes $69.4 \%$, hyperlipidaemia $30.6 \%$ and smoking $1.6 \%$. The prevalence of the major risk factors of hypertension and diabetes did not differ between the sexes. 
Table 1. Prevalence of co-morbidities and risk factors in patients diagnosed with stroke in Kuwait

\begin{tabular}{lccccc}
\hline Risk factor & $\begin{array}{l}\mathrm{M} \\
\mathrm{n}=30\end{array}$ & $\begin{array}{l}\mathrm{F} \\
\mathrm{n}=32\end{array}$ & $\begin{array}{l}\text { Total } \\
\mathrm{n}=65\end{array}$ & Percent & $\begin{array}{l}\text { General population } \\
\text { prevalence, \% }\end{array}$ \\
\hline Hypertension & 20 & 25 & 45 & 72.5 & $10-17[32]$ \\
Diabetes mellitus & 19 & 24 & 43 & 69.4 & $12[34]$ \\
Hyperlipidaemia & 12 & 7 & 19 & 30.6 & $>50[34]$ \\
Past history of TIA & 3 & 3 & 6 & 9.7 & NA \\
Cardiac disease & 7 & 8 & 15 & 24.2 & NA \\
Lone atrial fibrillation & 1 & 3 & 4 & 6.5 & NA \\
Migraine & - & 5 & 5 & 8.1 & NA \\
Smoking & 2 & 0 & 2 & 1.6 & M 50; F 9.4 [31] \\
\hline
\end{tabular}

$\mathrm{M}=$ Male $; \mathrm{F}=$ female; TIA = transient ischemic attack.
Table 2. Stroke subtype in relation to comorbidity and identifiable risk factors

\begin{tabular}{|c|c|c|c|c|}
\hline \multirow[t]{2}{*}{ Risk factor } & \multicolumn{3}{|c|}{ Stroke subtype } & \multirow{2}{*}{$\begin{array}{l}\text { Total } \\
\mathrm{n}=62\end{array}$} \\
\hline & $\begin{array}{l}\text { LAS } \\
\mathrm{n}=19\end{array}$ & $\begin{array}{l}\text { SAS } \\
\mathrm{n}=37\end{array}$ & $\begin{array}{l}\text { CES } \\
\mathrm{n}=6\end{array}$ & \\
\hline Hypertension & $15(78.9)$ & $26(70.3)$ & $4(66.7)$ & $45(72.5)$ \\
\hline Diabetes & $14(73.7)$ & $27(73.0)$ & $2(33.3)$ & $43(69.4)$ \\
\hline Cardiac origin & $6(31.6)$ & $4(10.8)$ & $5(83.3)$ & $15(24.2)$ \\
\hline Smoking & - & $1(2.7)$ & - & 1 (1.6) \\
\hline Hyperlipidaemia & $7(36.8)$ & $12(32.4)$ & $1(16.7)$ & $19(30.6)$ \\
\hline
\end{tabular}

Percentages in parentheses.

LAS = Large artery stroke, atherosclerotic aetiology; SAS = small artery stroke; CES = cardio-embolic stroke.

Table 3. Thirty-day stroke outcome (disability/death) in relation to stroke subtype

\begin{tabular}{lllll}
\hline Disability & \multicolumn{2}{l}{ Stroke subtype } & \multirow{2}{*}{$\begin{array}{l}\text { Total } \\
\mathrm{n}=62\end{array}$} \\
\cline { 2 - 4 } & LAS & SAS & CES & \\
& $\mathrm{n}=19$ & $\mathrm{n}=37$ & $\mathrm{n}=6$ & \\
\hline Not significant & $4(21.1)$ & $10(27.0)$ & - & $14(22.6)$ \\
Slight & $4(21.1)$ & $11(29.7)$ & $1(16.7)$ & $18(29.0)$ \\
Moderate & $3(15.8)$ & $8(21.6)$ & $1(16.7)$ & $12(19.4)$ \\
Moderately severe & $1(5.3)$ & $1(2.7)$ & - & $3(4.8)$ \\
Severe & $2(10.5)$ & $6(16.2)$ & $2(33.4)$ & $10(16.1)$ \\
Death & $5(26.3)$ & $1(2.7)$ & $2(33.3)$ & $8(12.9)$ \\
\hline
\end{tabular}

Percentages in parentheses.

LAS = Large artery; atherosclerotic aetiology; SAS = small artery stroke; CES = cardio-embolic stroke.

\section{Stroke Subtypes}

With respect to the location of the infarct, the anterior circulation was affected in $36(58 \%)$ of the 62 patients and the posterior circulation in $9(14.5 \%)$, while 4 patients $(6.5 \%)$ showed evidence of infarcts in both territories. Infarction in a small artery was the most common lesion, seen in $37(59.7 \%)$ subjects, large artery infarcts of atherosclerotic aetiology in $19(30.6 \%)$ patients and cardioembolic strokes in $6(9.7 \%)$ patients.

Thirty days after admission, $8(12.9 \%)$ patients had died ( 6 women and 2 men). The relative frequencies of the various degrees of residual disability and how these were related to the associated risk factors and co-morbidities of those still alive are shown in tables 2-4. Seven women $(22 \%)$ and 3 men $(10 \%)$ had severe disability. Conversely, 20 men $(66.7 \%)$ and 10 women (31.3\%) had slight or no significant disability, suggesting a generally worse outcome for women $(\mathrm{OR}=4.4)$. Age had a significant effect, as $18(90 \%)$ of patients who died or had severe disability were more than 60 years old $(\mathrm{p}<0.035)$. A greater proportion of deaths and severe disability occurred in patients with cardio-embolism (table 3), as well as among the subjects who were not on aspirin or other anti-platelet therapy (34.2\%) compared to $25 \%$ for those on anti-platelet therapy.

\section{Discussion}

Previous reports on stroke in Kuwait [11] and the Arabian Gulf Region [10, 12, 13, 23] have focused primarily on epidemiology and risk factors. This study, however, has provided additional information on the outcome of stroke, which is particularly important in planning long- 
Table 4. Thirty-day stroke outcome in relation to co-morbidities and risk factors

\begin{tabular}{lcclllll}
\hline Disability & \multicolumn{7}{l}{ Co-morbidity/risk factors } \\
\cline { 2 - 8 } & $\begin{array}{l}\mathrm{HP} \\
\mathrm{n}=45\end{array}$ & $\begin{array}{l}\mathrm{DM} \\
\mathrm{n}=43\end{array}$ & $\begin{array}{l}\mathrm{CO} \\
\mathrm{n}=15\end{array}$ & $\begin{array}{l}\mathrm{SM} \\
\mathrm{n}=1\end{array}$ & $\begin{array}{l}\text { HL } \\
\mathrm{n}=19\end{array}$ & $\begin{array}{l}\text { Mig } \\
\mathrm{n}=5\end{array}$ & $\begin{array}{l}\text { AF } \\
\mathrm{n}=4\end{array}$ \\
\hline Not significant & $8(17.8)$ & $10(23.3)$ & $4(26.7)$ & $1(100)$ & $7(36.8)$ & $2(40.0)$ & - \\
Slight & $12(27.7)$ & $11(26.7)$ & $2(13.3)$ & & $6(31.6)$ & $1(20.0)$ & $1(25.0)$ \\
Moderate & $10(22.2)$ & $10(23.3)$ & $2(13.3)$ & - & $3(15.8)$ & $1(20.0)$ & $1(25.0)$ \\
Moderately severe & $2(4.4)$ & $2(4.7)$ & - & - & $1(5.3)$ & - & - \\
Severe & $7(15.6)$ & $5(11.6)$ & $2(13.3)$ & - & $1(5.3)$ & $1(20.0)$ & $1(25.0)$ \\
Death & $6(13.3)$ & $5(11.6)$ & $5(33.3)$ & - & $2(10.0)$ & - & $1(25.0)$ \\
\hline
\end{tabular}

Percentages in parentheses.

$\mathrm{HP}=$ Hypertension; $\mathrm{DM}=$ diabetes mellitus; $\mathrm{CO}$ = cardiac origin; $\mathrm{SM}=$ cigarette smoking; $\mathrm{HL}=$ hyperlipidaemia; $\mathrm{Mig}=$ migraine; $\mathrm{AF}=$ atrial fibrillation.

term care for affected individuals. A drawback of this study is its relatively small sample size, as the study was limited to only one hospital in Kuwait. As such the study is preliminary, and a larger, longer-term study of stroke in the whole country is currently being planned. Nevertheless, inferences can still be drawn from the results of this study.

\section{General Aspects}

Almost as many women as men were affected, contrary to previous reports in which there was demonstrable male preponderance [11, 12]. This is surprising, as there was no age difference between male and female patients. Similarly, the prevalence of the major risk factors of hypertension and diabetes did not differ between the sexes.

\section{Stroke Subtypes and Risk Factors}

A previous study of stroke in Kuwait [11] reported infarction in the large carotid territory in $46.5 \%$ of cases, lacunar in $17 \%$, and involvement of the posterior circulation in $8.3 \%$. That study and others [23-26] have generally indicated that large-artery infarcts are more common than small-artery ones. In this study, however, lacunar infarcts were the most common (59.7\%), and were much more frequently seen than the large-artery infarcts (30.6\%). The difference in the pattern observed here from that in an earlier study [11] in the same population and other reports [23-26] might therefore reflect the effects of stress and increasing obesity [14]. The pattern of stroke subtypes reported in this study might also be explained by the unusually high frequency of hypertension and diabetes in our patients. Hypertension was present in $72 \%$ of our patients (table 1), while most other studies reported about $54 \%$ prevalence of hypertension in stroke patients [25-29]. Diabetes had a 69\% prevalence in our subjects, in contrast to the range of $14-42 \%$ reported in many other studies [11, 23, 27-28], including those from Kuwait [11] and Saudi Arabia [23]. The prevalence of hypertension and diabetes in this stroke population is up to three times that of the general population $(10-17 \%$, table 1$)$.

With respect to the other risk factors, cardiac disease was present in $24 \%$ of patients, similar to that reported in other studies [10-23]. The 5 subjects with migraine had other associated risk factors (4 had hypertension and 1 had diabetes; 2 of those with hypertension also had atrial fibrillation), which made it difficult to isolate migraine as an independent risk factor for stroke in this study. However, hemiplegic migraine can cause focal neurological deficit [30]. Also of some interest is the observation that cigarette smoking, which is widely prevalent in the Gulf Region [31], was relatively uncommon among the stroke patients in this study (1.6\% versus $9.4-50 \%$ among the general population, table 1), as was a prior history of a transient ischaemic attack. Furthermore, the prevalence of hyperlipidaemia in the study population was not much different from that reported in the general Kuwaiti population [32, 34] (table 1). Given the relatively low or normal prevalence rates of these risk factors and the high prevalence of hypertension and diabetes among this population, it is tempting to suggest that there is a relationship between atherosclerotic strokes and hypertension and diabetes. 


\section{Outcome}

Of concern in this study is the observation that the outcome was worse among women than men, with a higher percentage dying within 30 days or having severe disability. An analogous situation exists with regard to the prevalence of ischaemic heart disease in the population [33], where women are affected earlier and more severely than men. As, in general, women tend to be more obese than men [14], it is of interest whether obesity plays a role in these observations. The post-menopausal oestrogen loss in these women, almost all of whom were older than 50 years of age, might also have an effect on stroke outcome. These issues deserve further detailed evaluation.

As earlier indicated, diabetes and hypertension were the most important risk factors associated with stroke in this study. Both were about equally associated with smallartery (lacunar) and large-artery (atherosclerotic) strokes, and both had a significant association with death or severe disability at 30 days (tables 2, 4). They should therefore be managed aggressively in the prevention and treatment of stroke, especially when present with an underlying cardiac disease, as was the case in most of the deaths in the study (table 4).

The stroke subtype associated with the highest death rate $(62.5 \%)$ was the large-artery stroke (table 3 ), which is probably a reflection of the size of the infarct. Cardioembolic strokes also resulted in death and/or severe dis- ability in about two thirds of those affected, but antiplatelet therapy with aspirin and/or persantin appeared to have an ameliorative effect on risk of death and severe disability. Its early and effective use should therefore be encouraged in all appropriate cases.

\section{Conclusion}

Our findings indicate that stroke is common in $\mathrm{Ku}-$ wait, and its more important risk factors are diabetes, hypertension and coincidental cardiac disease. Lacunar ischaemic stroke was the most common subtype. Outcome as indicated by severe disability or death was worst among women, elderly patients and patients with large artery atherosclerotic and cardio-embolic strokes. Some evidence exists that such deleterious outcome might have been averted with prior use of anti-platelet drugs. These observations have implications for the aetiopathogenesis, prevention and management of this widespread disorder and form the focus of our continuing studies.

\section{Acknowledgements}

We would like to thank Mr. Suresh Nair for his secretarial assistance.

\section{References}

1 Bonita R: Epidemiology of stroke. Lancet 1992;339:342-344.

2 Hachinski V: Decreased incidence and mortality of stroke. Stroke 1984;15:376-378.

3 Wolf PA, D'Agostino RB, Belanger AJ, Kannel WB: Probability of stroke: A risk profile from the Framingham Study. Stroke 1991;22:312 318

4 Bronner LL, Kanter DS, Manson JE: Primary prevention of stroke. N Engl J Med 1995;333: 1392-1400

5 Gorelick PB: Stroke prevention. Arch Neurol 1995;52:347-355.

6 Kannel WB, Dawber TR, Cohen ME, McNamara PM: Vascular disease of the brain: Epidemiological aspects. The Framingham Study. Am J Public Health 1965;55:1355-1366.

7 Whishnant JP, Fitzgibbons JP, KurlandLT, Sayrle GP: Natural history of stroke in Rochester, Minnesota, 1945 through 1954. Stroke 1971;2:11-22.

8 Matsumoto N, Whishnant JP, Kurland LT, Okazaki N: Natural history of stroke in Rochester, Minnesota, 1965 through 1969: An extension of a previous study, 1945 through 1954. Stroke 1973;4:20-29.
9 Tanaka H, Ueda Y, Date C, Baba T, Yamashita H, Hayashi M, Shoji H, Owada K, Baba KI, Shibuya M, Kon T, Detels R: Incidence of stroke in Shibata, Japan, 1976-1978. Stroke 1981;12:460-466.

10 Al-Rajeh S, Larbi E, Bademosi O, Awada A, Ismail H, Al-Freihi H, Al-Ghassab G: Stroke in a tertiary hospital in Saudi Arabia: A study of 372 cases. Eur Neurol 1991;31:251-256.

11 Abdul-Ghaffar NU, El-Sonbaty MR, El-Din Abdul-Baky MS, Marafie AA, Al-Said AM: Stroke in Kuwait: A three-year prospective study. Neuroepidemiology 1997;16:40-47.

12 Al-Rajeh S, Larbi EB, Bademosi O, Awada A, Yousef A, Al-Freihi H, Miniawi H: Stroke register: Experience from the eastern province of Saudi Arabia. Cerebrovasc Dis 1998;8:8689.

13 Awada A, Al-Rajeh S: The Saudi Stroke Data Bank Analysis of the first 1000 cases. Acta Neurol Scand 1999;100:265-269.

14 al-Isa AN: Prevalence of obesity among adult Kuwaitis: A cross-sectional study. Int J Obes Relat Metab Disord 1995;19:431-433.
15 World Health Organization: Cerbrovascular diseases: Prevention, treatment and rehabilitation. World Health Organ Tech Rep Ser 1971; 469.

16 MacMahon S, Rodgers A: The epidemiological association between blood pressure and stroke: Implications for primary and secondary prevention. Hypertens Res 1994;17(suppl 1):S23S32.

17 Anonymous. Report of the Expert Committee on the Diagnosis and Classification of Diabetes Mellitus. Diabetes Care 2000;25(suppl 1):S5S20.

18 Expert Panel on Detection, Evaluation and Treatment of High Blood Cholesterol in Adults: Executive summary of the Third Report of the National Cholesterol Education Program (NCEP) Expert Panel on Detection, Evaluation and Treatment of High Blood Cholesterol in Adults (Adult Treatment Panel III). JAMA 2001;285:2486-2497.

19 Adams HP Jr, Bendixen BH, Kappelle LJ, Biller J, Love BB, Gordon DL, Marsh EE 3rd: Classification of subtype of acute ischemic stroke. Definitions for use in a multicenter clinical trial. TOAST. Trial of Org 10172 in Acute Stroke Treatment. Stroke 1993;24:35-41

Al-Shammri/Shahid/Ghali/Mehndiratta/ Swaminathan/Chadha/Sharma/Akanji 
20 Damasio H: A computed tomographic guide to identification of cerebral vascular territories. Arch Neurol 1983;40:138-142.

21 Bamford J, Sandercock P, Jones L, Warlow C: The natural history of lacunar infarction: The Oxfordshire Community Stroke Project. Stroke 1987;18:545-551.

22 Bonita R, Beaglehole R: Recovery of motor function after stroke. Stroke 1988;19:14971500 .

23 Al-Rajeh S, Awada A, Niazi G, Larbi E: Stroke in a Saudi Arabian National Guard Community. Stroke 1993;24:1635-1639.

24 Kurtzke JF, Kurland LT: Epidemiology of neurological disease; in Baker AB, Joynt RJ (eds): Clinical Neurology. Philadelphia, Harper and Row, 1987, vol 4

25 Mohr JP, Caplan LR, Melski JW, Goldsten RJ, Duncan GW, Kistler JP, Pessin MS, Bleich HL: The Harvard Co-Operative Stroke Registry: A prospective registry. Neurology 1978;28: 754-762.
26 Barnett HJ: Heart in ischemic stroke - a changing emphasis. Neurol Clin 1983;1:291-315.

27 Bogousslavsky J, Van Melle G, Regli F: The Lausanne Stroke Registry: Analysis of 1000 consecutive patients with first stroke. Stroke 1988;19:1083-1092.

28 Lefkovits J, Davis SM, Rossiter SC, Kilpatrick CJ, Hopper JL, Green R, Tress BM: Acute stroke outcome: Effects of stroke type and risk factors. Aust NZ J Med 1992;22:30-35.

29 D’Alessandro G, Giovanni MD, Roveyaz I, Iannizii L, Iannizzi L, Compagnoni MP, Blanc $\mathrm{S}$, Bottacchi E: Incidence and prognosis of stroke in the Valle d'Aosta, Italy. First-year results of a community-based study. Stroke 1992;23:1712-1715.

30 Whitty CWM: Familial hemiplegic migraine; in Rose FC (ed): Handbook of Clinical Neurology. New York, Elsevier, 1986, pp 141-153.
31 Bener A, Gomes J, Anderson JA: Smoking habits among physicians in two Gulf countries. J R Soc Health 1993;113:298-301.

32 Akanji AO, Al-Sulaiman A, Kinatamitath P Safar S, Al-Zaid K, Mojiminiyi OA: Profile of hyperlipidaemic patients in Kuwait: Frequency of cardiovascular disease risk factors at presentation and initial response to treatment. J Kuwait Med Assoc 1997;29:25-33.

33 Kanaya AM, Grady D, Barrett-Connor E: Explaining the sex difference in coronary heart disease mortality among patients with type 2 diabetes mellitus: A meta-analysis. Arch Intern Med 2002;162:1737-1745.

34 Abdella N, Al-Arouj M, Al-Nakhi A, Al-Assoussi A, Moussa M: Non-insulin-dependent diabetes in Kuwait: Prevalence rates and associated risk factors. Diabetes Res Clin Pract 1998;42:187-196. 